\title{
Non-suicidal self-injury (NSSI) and suicidal: Criteria differentiation
}

\author{
Joanna Halicka ${ }^{B-D}$, Andrzej Kiejna ${ }^{A}$ \\ Department and Clinic of Psychiatry, Wroclaw Medical University, Poland \\ A - research concept and design; $B$ - collection and/or assembly of data; $C$ - data analysis and interpretation; \\ $\mathrm{D}$ - writing the article; $\mathrm{E}$ - critical revision of the article; $\mathrm{F}$ - final approval of the article
}

\section{Address for correspondence}

Joanna Halicka

E-mail: joannahalicka@op.pl

\section{Funding sources \\ None declared}

Conflict of interest

None declared

Received on August 22, 2016

Reviewed on 0ctober 2, 2016

Accepted on 0ctober 25, 2016

\begin{abstract}
There are 2 types of basic self-destructive behavior: suicide and non-suicidal self-injury (NSSI). Currently, more and more researchers point out significant disorders which are NSSI behavior. This phenomenon is not new; NSSI seemingly has always been present in society, and certainly in approx. 10\% of the population worldwide in recent times. Despite the enormous scale of the phenomenon, so far it has been overlooked and marginalized. They were considered transient behavior, typical of adolescence, a part of youthful rebellion. Current research indicates that the disorder affects the adult population in almost equal measure. It is only in the latest diagnostic classification - Diagnostic and Statistical Manual of Mental Disorders, Fifth edition (DSM-5) by American Psychiatric Association - that has considered NSSI a separate class of behavior. Up to now, it was classified as a prelude to suicide or an element of personality disorders. NSSI is more commonly associated with disturbing behavior and suicide attempts.
\end{abstract}

Key words: non-suicidal self-injury, suicide, suicide attempt

DOI

10.17219/acem/66353

\section{Copyright}

Copyright by Author(s)

This is an article distributed under the terms of the

Creative Commons Attribution Non-Commercial License

(http://creativecommons.org/licenses/by-nc-nd/4.0/) 


\section{Introduction}

There are 2 types of basic auto-destructive behavior: suicide and non-suicidal self-injury (NSSI). There are a number of distinguishing criteria, but the main one is the intention of death.

According to World Health Organization (WHO), suicide is a multidimensional phenomenon, resulting from the interaction between biological, psychological, genetic, and environmental factors. ${ }^{1}$ According to the definition, suicide is the deliberate termination of life, and legal definition is extended with the statement that the death is a result of the direct or indirect action or negligence of the victim, who fully realizes the effect of their actions. ${ }^{2}$

NSSI has been defined by the International Society for the Study of NSSI as the deliberate, self-inflicted destruction of body tissue without suicidal intent and for purposes not socially sanctioned. NSSI can be divided due to its features and forms. The features are positive reinforcement, addition of desired stimulus, or negative reinforcement or subtraction of unwanted stimulus. NSSI is expressed in various forms from relatively mild, such as scratching, plucking hair or interfering with wound healing, to relatively severe forms, such as cutting, burning or hitting. ${ }^{3}$

The Diagnostic and Statistical Manual of Mental Disorders, Fifth Edition (DSM-5), published in the year 2013, ${ }^{4}$ qualifies NSSI as a separate entity, among the disorders requiring further research. The proposed criteria for DSM5 include the following:

- intentional self-inflicted injury performed with the expectation of physical harm, but without suicidal intent, on 5 or more days in the past year;

- the behavior is performed for at least 1 of the following reasons:

- to relieve negative thoughts or feelings;

- to resolve an interpersonal problem;

- to cause a positive feeling or emotion;

- the behavior is associated with at least 1 of the following:

- negative thoughts or feelings, or interpersonal problems that occur immediately prior to engaging in NSSI;

- preoccupation with NSSI that is difficult to resist;

- frequent urge to engage in NSSI;

- the behavior is not socially sanctioned and is more significant than nail biting or picking at a scab;

- the behavior causes clinically significant distress or impairment;

- the behavior does not occur exclusively in the context of another disorder and cannot be accounted for by another mental or medical disorder.

\section{Objectives}

The aim of the study was to differentiate between the self-destructive behaviors NSSI and suicide.

\section{Methods}

Using the Scopus, PubMed, EBSCO, Google Scholar, and Web of Science databases, medical literature on the topics of suicide and NSSI were searched and 12 differentiation criteria were created between the self-destructive behaviors suicide and NSSI.

\section{Results}

NSSI is commonly although incorrectly called suicide attempts. This misuse of the term occurs just as frequently in clinical practice and entails improper treatment of the patient. Therefore, it is important to tell these phenomena apart. So far in Polish literature, there have been no articles on the distinction between these behaviors. Below there are the 12 determinants by means of which NSSI can be distinguished from suicide attempts.

Table 1 explains the differences between a suicide attempt and NSSI (author's own work, after Walsh, 2006).

The fundamental criterion for distinguishing between non-suicidal self-destructive behaviors and suicide is the intention of death. ${ }^{5}$ According to Shneidman, suicide involves not so much the desire to kill the body, but the wish to end one's own consciousness. ${ }^{6}$ NSSI, in turn, has 2 functions. One of them is negative reinforcement and removing unwanted stimuli, i.e., dismissing unpleasant emotional states. ${ }^{5,6}$ The most common categories of unpleasant emotional states declared by NSSI are fear, sadness, shame or guilt, tension, anxiety or panic, frustration, and contempt. The share and severity of these emotions varies individually. ${ }^{6}$ The other function of NSSI is positive reinforcement - to boost a desired stimulus, i.e., to provide stimulation by experiencing strong emotions and get rid of the feeling of emptiness, which takes place in the vast minority of cases. ${ }^{7}$

Babikier and Armond suggest a different division of functions of NSSI: functions related with managing and surviving, functions related with ego and proper experience, and functions connected with punishing oneself and being a victim. ${ }^{8}$ NSSI is a way of coping and it is a means of surviving, as it reduces tension and fear, helps to manage anger and it is applied to avoid or focus on pain in order to control it. An individual copes with unbearable feelings to distract oneself from fear and tension, and to pay attention to other, more attainable behaviors, such as self-harm. The functions of NSSI related with ego include reinforcement of a sense of control, intensification of a sense of reality and breaking the states of dissociation. The pain that accompanies NSSI is often an important element of the process of regaining the sense of self-control and integration of an individual. Another function of NSSI is creating opportunities to take care of oneself. In some individuals, the period following NSSI is the only moment when they allow themselves to feel relieved and experience physical care. On the other hand, coping with one's 
Table 1. Criteria for differentiation of direct self-destructive behaviors

\begin{tabular}{|c|c|c|}
\hline Criterion & Suicide & NSSI \\
\hline Primary intention & intention to die & preservation of life, destruction of the body \\
\hline General intention & escape from mental pain and consciousness & $\begin{array}{l}\text { escape from mental pain and transformation into } \\
\text { physical pain }\end{array}$ \\
\hline Functions & reduction of tension, a sense of relief & $\begin{array}{c}\text { managing and surviving (e.g., reduction of tension } \\
\text { and fear), functions connected with ego, functions } \\
\text { connected with proper experience, punishing oneself, } \\
\text { providing stimulation }\end{array}$ \\
\hline Potential death & high degree of mortality & low degree of mortality \\
\hline Number of methods used & usually one & usually many (the number increases over time) \\
\hline Chronicity & rarely & often \\
\hline Mental pain & persistent, unbearable & discontinuous \\
\hline Cognitive narrowing & high, suicide seen as the only solution & low or none \\
\hline Hopelessness and helplessness & constant, occupies a central place & variable, does not dominate \\
\hline $\begin{array}{l}\text { Consequences in terms of the } \\
\text { recognition of discomfort }\end{array}$ & discomfort intensifies after suicide attempt & discomfort decreases after NSSI \\
\hline Associated disorders & $\begin{array}{l}\text { psychotic disorders (schizophrenia), affective } \\
\text { disorders, alcohol abuse, anxiety disorders }\end{array}$ & $\begin{array}{l}\text { personality disorders, addictions, eating disorders, } \\
\text { posttraumatic stress disorder }\end{array}$ \\
\hline Main issue & depression, mental pain unbearable & negative image of ego \\
\hline
\end{tabular}

experience is expressed by experiencing again the feelings and traumas which had been denied previously, as well as by manifesting toward oneself their own experiences. Punishing oneself is also a significant function of NSSI, most frequently related with a negative image of oneself created in the period of childhood or under the influence of a traumatic experience. ${ }^{8}$

NSSI and suicide attempts also differ by their mortality rate, which results from the nature of the forms of self-destruction. The most common methods of suicide in Poland are hanging oneself $-75.04 \%$, jumping from a height $-7.11 \%$, poisoning $-4.49 \%$, and jumping in front of a vehicle $-2.27 \% .{ }^{9}$ Suicide attempts are fatal in $10-20 \%$ of all cases, while other self-destructive behavior ends in death in $0.6 \%$ of cases and are most often caused by cutting an artery. ${ }^{5,10,11}$ However, according to Whitlock et al., NSSI usually takes the form of: scraping the skin $-51.6 \%$; beating - 37.6\%; cutting - 33.7\%; bruising - 24.5\%; cutting symbols in the skin - $14.9 \%$; scratching wounds $-13.5 \%$; piercing with sharp objects $-12 \%$; and plucking hair $-11 \% .{ }^{12}$ A general review of the literature shows that the most common methods of NSSI include cutting the skin, hitting oneself, scratching wounds, bruising, and biting. ${ }^{6,8}$ Thus, suicide and NSSI involve different methods.

Another point of distinction between self-harm behavior is the number of methods used. Those making suicide attempts use the same method when making another suicide attempt. ${ }^{13}$ Most people repeatedly attempt suicide by drug overdose. ${ }^{6}$ In contrast, $78 \%$ of people who practice nonlethal self-injurious behavior use more than 1 method. ${ }^{14}$ The use of more methods is related mainly to preferences. Many people using NSSI say they use a variety of methods depending on their mood. For example, some people engaged in NSSI claim that they cut their skin when they are emotionally wrecked, and hit themselves when experiencing nervousness. Others cut their skin when experiencing anxiety and burn themselves under nervousness. The scope of relations between the form of self-harm and the type of emotion is nearly infinite. ${ }^{15}$

Another issue that tells these types of behavior apart is the frequency of their occurrence. NSSI episodes in one person take place much more often than suicide attempts. Most people attempting suicide do it neither frequently nor repeatedly. Suicide attempts are usually made once or twice in a lifetime, in one's most stressful period of life. ${ }^{15}$ However, the number of NSSI episodes is approx. 20-100 times over the course of several years. ${ }^{11}$ The frequency of NSSI among teenagers may reach up to 20-30 episodes per year. ${ }^{5}$

The differences between the types of aggressive behavior are also seen in the level of psychological pain, which, like cognitive narrowing, is higher for suicidal behavior than NSSI. ${ }^{5}$ According to Ringel's concept, around 80\% of suicides are related to the narrowing of consciousness, which, apart from anger inhibition and directing it at oneself and suicidal thoughts, is an element of pre-suicidal syndrome. The narrowing of consciousness occurs when an individual does not perceive alternative forms of solving a problem (tunnel vision). Suicide attempts are preceded by dichotomous thinking, where the alternative is death. Hopelessness and helplessness in the face of mental pain are more often experienced by future suicides than NSSI, who do not declare their lack of control over pain; on the contrary, NSSI helps them maintain a sense of control. ${ }^{16}$ NSSI is not characterized by dichotomous thinking. People engaged in NSSI are usually rather disorganized than limited in terms of their way of thinking. They do not limit their life to all-or-nothing attitudes. They consider 
themselves to be capable to make life choices. One of those choices is the decision to harm themselves.

Research on suicide has long identified a sense of both hopelessness and helplessness as essential component of depression and suicidal behavior. ${ }^{17-19}$ The feeling of helplessness, which involves the lack of hope, refers to the loss of control. ${ }^{18}$ People who feel helpless believe that they have no real influence or real control over their situation. They are convinced that there is nothing they could do to change or improve their lives. Such cognitive pessimism is very characteristic of "surrender", which is part of suicide. The feeling of helplessness of people committing suicide is well illustrated by Beck's triad of depression. ${ }^{17}$ In this perspective, people with suicidal tendencies think: "I am angry, the world is a hostile place and the future is unchangeable."

On the other hand, helplessness and hopelessness are not characteristic of people hurting themselves. Such people usually do not have a sense of lack of control over their physiological pain, which de facto conditions this sense of control. Control resulting from NSSI is the opposite of hopelessness. The future is not seen as a great suffering, because NSSI reduces emotional tension. An individual's psychological discomfort and crippling pessimism are temporary. Their suffering lacks a sense of permanence, which is typical of a suicidal crisis.

Muehlenkamp and Gutierrez made a comparative study of teenagers engaged in NSSI. ${ }^{20}$ Their research showed that people engaged in self-injury without suicidal intentions were characterized by a lower rate of hopelessness, stronger future-orientation, more developed motivation to live as compared to people undertaking a suicide attempt. These results confirm the hypothesis that the level of emotional pain varies depending on the type of selfdestructive behavior.

The difference is also observed in terms of psychological consequences. After a failed suicide attempt, a person usually experiences a worsening of mood, the feeling of failure associated with the fact they failed to commit suicide successfully. NSSI, on the other hand, is done to reduce tension, and as a result, a person usually experiences relief and an improved frame of mind. ${ }^{5}$

Research indicates that some disorders accompany suicide attempts, while others are associated with NSSI. Approximately $90 \%$ percent of suicides are associated with at least 1 psychiatric disorder. ${ }^{21}$ The risk of committing suicide over a lifetime is $30.2 \%$ for the general population of the mentally ill. ${ }^{2,21}$ These are mainly depressive disorders, addictions, cluster B personality disorders, and schizophrenia. ${ }^{24}$ Schizophrenia is associated with the highest elevated risk of suicide. About $40-50 \%$ of schizophrenia patients have suicidal thoughts at some point in life, and $4-13 \%$ commit suicide, making it a leading cause of premature death among patients. ${ }^{23}$ In addition, the risk of a suicide attempt is increased by $30 \%$ in those patients suffering from schizophrenia who have symptoms of depression. ${ }^{24}$ Depressive disorders and alcohol abuse are placed second and third, respectively. ${ }^{1}$ Suicidal behaviors are also largely related to anxiety disorders. The risk of suicide is further increased if anxiety and personality disorders are observed collectively. ${ }^{25}$ Other important disorders associated with suicide are affective disorders. The risk of suicide in these patients is around $30-40 \% .{ }^{26}$ Throughout the course of life, suicidal behavior affects an average of $4 \%$ of people with mood disorders and $8 \%$ of those with bipolar disorder. ${ }^{1}$

By contrast, NSSI are often linked to destructive mental disorders, such as alcohol and drug abuse, eating disorders and personality disorders, and are observed in patients suffering from posttraumatic stress disorder (PTSD). ${ }^{27,28}$ Up to $79 \%$ of those suffering have experienced violence or rejection in childhood. ${ }^{28} \mathrm{Up}$ to $50 \%$ of cases of selfdestructive behaviors are associated with alcohol abuse. ${ }^{1}$ In the context of substance abuse and addictions related to self-destructive behaviors, in its therapy it is necessary in the first place to deal with the substance abuse, which is the base for other self-destructive behaviors. The next step is to deal with the self-harm which derives from the addictions and substance abuse. Amongst the aforementioned behaviors, addictions and substance abuse are the easiest to overcome, which is caused by the fact that for a self-harming individual it is hard to function without self-harm, and at the same time self-harm seems the mildest means of selfdestruction that enables the individual's existence. ${ }^{10}$

The source of the problems of people with suicidal tendencies fluctuates around depression, sadness and rage due to the primary source of pain. Maltsberger showed that suicides are caused not only by sadness, isolation and loneliness, but also include an element of "murderous hatred". ${ }^{29}$ This hatred is directed both inward and outward. Help for those making suicide attempts is to rely on finding and reducing the original source of pain. Shneidman emphasizes that the task of the therapist is to add a third component to the dichotomous thinking in people with suicidal tendencies, one that reduces the risk of a suicide attempt. ${ }^{6}$ Finding the source of unbearable suffering should be the first element in working with people at risk of suicide. The more accurate the clarification of the source, the more efficient the therapeutic work.

In contrast, research shows that the source of the problem in NSSI is a distorted body image. ${ }^{6}$ The feeling of being cut off from the body or hatred toward the body leads to NSSI. The key question in the treatment of the source of self-injury should be: "What are the sources of such a relationship with one's body?" and "Why do you keep trying to inflict harm on your body?" 


\section{Summary and discussion}

As it has been shown, suicides and NSSI differ in many respects. These differences are primarily qualitative. These behaviors are caused by other factors, they have a different intent and serve different functions. NSSI and those making a suicide attempt also suffer different consequences and psychological after-effects. ${ }^{5}$ One should also pay attention to the coexistence of these self-destructive behaviors; NSSI often precedes a suicide attempt, as the individual embraces the notion of self-destruction, to start later using more and more destructive methods. NSSI youths are 3 times more likely to experience suicidal thoughts and attempt suicide. ${ }^{11}$ Long-term NSSI often precedes suicide, even though the individual showed no intention of death at first. ${ }^{30}$

Recent years have brought a lot to the understanding of NSSI. Both NSSI and suicide attempts are phenomena of enormous magnitude. NSSI involves $7-14 \%$ of the population worldwide ${ }^{6}$ and applies to $15-28 \%$ of young people, ${ }^{27,30}$ and on average begins between 12 and 14 years of age. ${ }^{31,32}$ However, according to WHO data, suicide is one of the 20 most common causes of death among the total population and represents one of the most common causes of death among young people. ${ }^{33}$ Further research on the various types of self-destructive behavior is needed for a full understanding of the problem and to determine the appropriate directions of therapeutic work. Incorrect diagnosis of self-destructive behavior can cause inefficient therapeutic work, and even intensify the severity of the disorder occurrence.

\section{References}

1. World Health Organization: WHO. http://www.who.int/topics/suicide/en/

2. Putowski M, Piróg M, Podgórniak M, Zawiślak J, Piecewicz-Szczęsna H. Analiza epidemiologiczna występowania samobójstw w Polsce w latach 2000-2013. Probl Hig Epidemiol. 2015;96(1):264-268.

3. Gratz KL, Conrad SD, Roemer L. Risk factors for deliberate self-harm among college students. Am J Orthopsychiatry. 2002;72:128-140.

4. American Psychiatric Association, ed. Diagnostic and Statistical Manual of Mental Disorders. $5^{\text {th }}$ ed. Washington, DC: American Psychiatric Association; 2013.

5. Walsh B. Treating Self-Injury: A Practical Guide. New York, NY; Guilford Press; 2006.

6. Shneidman E. Definition of Suicide. New York, NY: John Wiley \& Sons; 1985:202-213.

7. Whitlock J, Muehlenkamp JJ, Eckenrode J. Variation in non-suicidal self-injury: Identification and features of latent classes in a college population of emerging adults. J Clin Child Adolesc Psychol. 2008;37:725-735.
8. Babiker G, Arnold L. Autoagresja, mowa zranionego ciała. Gdańsk: Gdańskie Wydawnictwo Psychologiczne; 2003.

9. Serwis policja.pl. www.policja.pl

10. Walsh B, Rosen P. Self-Mutilation:Theory, Research and Treatment. New York, NY: Guilford Press; 1988.

11. Conterio K, Lader W. Bodily Harm: The Breakthrough Healing Program for Self Injurers. New York, NY: Hyperion Press; 1998.

12. Whitlock JL, Eckenrode J, Silverman D. Self-injurious behaviors in a college population. Pediatrics. 2006;117:1939-1948.

13. Berman AL, Jobes DA, Silverman MM. Adolescent Suicide: Assessment and Intervention. $2^{\text {nd }}$ ed. Washington, DC: American Psychological Association; 2006

14. Whitlock J, Muehlenkamp J, Eckenrode J, et al. Nonsuicidal self-injury as a gateway to suicide in adolescents and young adults. $J$ Adolesc Health. 2013;52:486-492.

15. Nock MK, Kessler RC. Prevalence of and risk factors for suicide attempts versus suicide gestures: Analysis of the National Comorbidity Survey. J Abnorm Psychol. 2006;115:616-623.

16. KubiakA. Mechanizm radzenia sobiez napięciem u osób podejmujących nawykowe samouszkodzenia. 2013. [Unpublished doctoral thesis.]

17. Beck AT, Rush, AJ, Shaw BF, Emery G. Cognitive Therapy of Depression. New York, NY: Guilford Press; 1979.

18. Seligman MEP. Helplessness: On Depression, Development, and Death. San Francisco, CA: W.H. Freeman; 1975. (Paperback reprint edition, W.H. Freeman; 1992.)

19. Milnes $D$, Owens $D$, Blenkiron P. Problems reported by self-harm patients: Perception, hopelessness and suicidal intent. J Psychosom Res. 2002;53:819-822.

20. Muehlenkamp J, Gutierrez PM. Risk for suicide attempts among adolescents who engage in non-suicidal self-injury. Arch Suicide Res. 2007:11:69-82.

21. Harris EC, Barraclough B. Suicide as an outcome for mental disorders. A meta-analysis. J Psychiatry. 2007; Mar;170:205-28.

22. Rosa K. Młodzież podejmująca próby samobójcze. Charakterystyka socjologiczna. Przegl Lek. 2007;1:24-30.

23. McGirr A, Renaud J, Bureau A, Seguin M, Lesage A, Turecki G. Impulsive-aggressive behaviors and completed suicide across the life cycle: A predisposition for younger age of suicide. Psychol Med. 2006;38(3):407-417

24. Radomsky ED, Gretchen JJ, Mann, Sweeney JA. Suicidal behavior in patients with schizophrenia and other psychotic disorders. Am J Psychiatry. 1999;156:1590-1595.

25. Sareen J, Afifi TO, McMillan KA, Asmundson GJ. Relationship between household income and mental disorders: Findings from a population-based longitudinal study. Arch Gen Psychiatry. 2011;68(4):419427.

26. Bostwick JM, Pankratz SV. Affective disorders and suicide risk: A reexamination. Am J Psychiatry. 2000;157:1925-1932.

27. Kerr PL, Muehlenkamp JJ, Turner JM. Nonsuicidal self-injury: A review of current research for family medicine and primary care physicians. JABFM. 2010;23(2):240-259.

28. Yates, TM. The developmental psychopathology of self-injurious behavior: Compensatory regulation in posttraumatic adaptation. Clin Psychol Rev. 2004;24(1):35-74.

29. Maltsberger JT. Suicide Risk. The Formulation of Clinical Judgment. New York, NY: University Press; 2013.

30. Cooper J, Biddle L, Owen-Smith A, et al. Suicide after deliberate selfharm: A 4-year cohort study. Am J Psychiatry. 2006;162(2):297-230.

31. Ross S, Heath NL. A study of the frequency of self-mutilation in a community sample of adolescents. J Youth Adolescence. 2002;31:67-77.

32. Whitlock J, Knox KL. The relationship between self-injurious behavior and suicide in a young adult population. Arch Pediatr Adolesc Med. 2007;161:634-640.

33. Nock M, Prinstein MA. Functional approach to the assessment of self-mutilative behavior. J Consult Clin Psychology. 2004;2(5):885-890. 